\author{
LA INMUNIDAD PARLAMENTARIA * \\ POR \\ ANTONIO CARRO MARTINEZ \\ Letrado del Consejo de Estado
}

\begin{abstract}
SUMARIO
I. Delimitación.-II. Naturaleza.-III. Origen histórico.-IV. Inmunidad e inviolabilidad.-V. Otras justificaciones.-VI. Inmunidad en las Cortes de Cádiz.-VII. Inmunidad en la Monarquía constitucional.-VIII. II República.-IX. Régimen autoritario.-X. Monarquía parlamentaria.-XI. Sistemas comparados.-XII. Inmunidad y futuro.
\end{abstract}

\title{
I. DELIMITACION
}

La palabra «inmunidades» es utilizada en Derecho parlamentario como sinónima de ciertas excepciones, prerrogativas o privilegios de que gozan los diputados y senadores para mejor garantizar el ejercicio de su función. Estas inmunidades comprenden fundamentalmente la inviolabilidad por las opiniones manifestadas en actos parlamentarios, que el Derecho francés denomina muy apropiadamente «irresponsabilidad», y la inmunidad strictu sensu, que en el país vecino se conoce como «inviolabilidad», y que es la prerrogativa de no ser detenidos, presos, procesados ni juzgados sin previa autorización del respectivo Cuerpo colegislador.

El presente trabajo va a estudiar esta última idea, conocida en nuestro Derecho como la inmunidad parlamentaria por antonomasia, a sabiendas de que se trata de una prerrogativa que está cayendo en desuso en el Derecho parlamentario comparado, por ser una excepción, un privilegio, y una singularidad, que choca frontalmente contra el superior principio de la igualdad de todos los ciudadanos ${ }^{1}$.

* Trabajo realizado para el libro jubilar del profesor Mesa Moles, de Granada.

1 Se trata de un principio superior, porque la igualdad ha sido elevada a categoría de dogma político en la Declaración de Derechos del Hombre y del Ciudadano, de 1789, que comienza su artículo $11^{\circ}$ por la siguiente afirmación: «Los hombres nacen y permanecen libres e iguales en derechos.» 
En consecuencia con dicho principio, la vigente Constitución afirma que todos los españoles son iguáles ante la Ley, sin que pueda prevalecer discriminación alguna por razón de cualquier otra condición o circunstancia personal ${ }^{2}$. No obstante esta contundente afirmación, la propia Constitución la excepciona seguidamente en favor de los que se hallen investidos de la condición de diputados y senadores, puesto que, además del habeas corpus y otras garantías generales ${ }^{3}$, establece el privilegio, prerrogativa o singularidad de que no pueden ser detenidos, inculpados ni procesados sin la previa autorización de la Cámara respectiva ${ }^{4}$.

Esta inmunidad especialísima se halla consagrada por una tradición parlamentaria muy consolidada y aceptada por el Derecho constitucional de casi todos los países. Los Estados Unidos de América reconocieron dicho privilegio en el más antiguo texto constitucional vigente ${ }^{5}$, y doscientos años más tarde lo sigue reconociendo también la novísima Constitución de la URSS ${ }^{6}$.

Ambos casos se traen a colación por ser polos de referencia de singular valor ejemplificador, aunque sólo resulten válidos a efectos nominales, pues la inmunidad tiene un alcance distinto en la diversa orografía política, y, muy especialmente en España, reviste un significado práctico muy singular.

Es bastante corriente que la inmunidad haya desbordado de hecho sus justos límites. Algunas veces ni siquiera ha servido de freno al revanchismo político, pero es que en la mayoría de los casos la inmunidad ha sido utilizada - como muy gráficamente ha expresado Bugallal - para crear «una categoría de español con billete de libre circulación permanente a través del Código Penal y endosable a los amigos» ${ }^{7}$. En fin, sería deseable - en palabras de Silvela- que la inmunidad no sea siempre una carta de impunidad ${ }^{8}$.

2 Artículo 14 de la vigente Constitución de 1978.

${ }^{3}$ Ibid., art. 17.

${ }^{4}$ Ibíd., art. 71.2 .

5 El art. 1, secc. 6, núm. 1 de la Constitución de 1787 , determina que «durante el petíodo de sesiones de sus respectivas Cámaras, así como mientras se dirijan a las mismas o de ellas regresen, no podrán ser arrestados (los senadores y representantes), excepto en casos de traición, delito grave y alteración de la paz».

- La Constitución de 7 de octubre de 1977, en el párrafo 2 del artículo 106, dispone que «la inmunidad de los diputados y otras garantías de su actividad son definidos en la Ley sobre el Estatuto de los Diputados y otras Leyes de la URSS y de la Unión y Repúblicas autónomas».

${ }^{7}$ Gabino Bugallal, Inviolabilidad parlamentaria, publicación de la Real Academia de Ciencias Morales y Políticas, Madrid, 1921, pág. 12.

${ }^{8}$ Francisco Silvela desea que la Constitución de 1876, discreta y previsora, pueda «facilitar la deseada reforma de las costumbres políticas en el sentido de que la inmunidad parlamentaria no se convierta en una impunidad, como la establecida entre nosotros, con un amplio y generoso espíritu de imparcialidad política, es verdad amparando por igual, y salvo bien raras excepciones, mayorías y minorías, a amigos y a adversarios, pero desnaturalizando evidentemente el pensamiento y elevados propósitos en que se inspiró esa garantía» (véase La inmunidad parlamentaria, en «Rev. General de Legislación y Jurisprudencia», año XXXVIII, tomo 76, pág. 48). Véase también Conde Tejada de Valdosera, De la indole y extensión de las inmunidades parlamentarias (discurso de ingreso en la Real Academia de Ciencias Morales y Políticas el 18 de febrero de 1894); Benito y Varela, La inviolabilidad parlamentaria, Madrid, 1894; González Regueral, La inviolabilidad y la inmunidad (tesis doctoral), Madrid, 1915. 


\section{NATURALEZA}

Hasta aquí se han venido utilizando indistintamente palabras como inmunidad, prerrogativa y privilegio. Todas estas palabras tienen su matiz diferenciador, e importa decantar sus características.

Los privilegios son derechos o facultades discriminadores y por encima de la norma general. En el caso de la inmunidad, se trata de una singularidad favorecedora del Parlamento y de los parlamentarios. Su esencia es personal, subjetiva, y marginal a la Ley común.

Las prerrogativas son una especie de poderes o potestades inherentes al Estado, y especialmente en el caso que nos ocupa se trata de potestades propias del Parlamento y los parlamentarios en cuanto instituciones del Estado y para el mejor ejercicio de su función 9 . Las prerrogativas son algo objetivo y anexo a la función del órgano o persona que las detenta. Son complemento y parte del Derecho común; nunca lo contradice ni excepciona.

Las inmunidades, por su parte, son derechos singulares que dispensan o excepcionan los principios fundamentales del sistema jurídico. Según Ferrara, la inmunidad es un derecho contratio a los principios ${ }^{10}$; es, en definitiva, un ius singulare que se adiciona y complementa al ordenamiento jurídico general.

Desde un punto de vista teórico y doctrinal, la inmunidad parlamentaria es una típica prerrogativa funcional, lo que es compatible con las propias esencias de la idea de inmunidad. Por el contrario, la idea de privilegio es contraria y no cabe dentro del concepto de Estado igualitario y democrático.

Desde un punto de vista práctico e histórico, fuerza es reconocer que la inmunidad ha nacido y ha venido funcionando como verdadero privilegio de los parlamentarios. Menor dificultad produce si dichos privilegios se atribuyen a la institución parlamentaria en lugar de recaer sobre los miembros de los Parlamentos.

Efectivamente, en Inglaterra, donde la freedom from arrest viene funcionando con ejemplaridad, no existe dificultad alguna en considerarla como un privilegio del Parlamento ${ }^{11}$.

Por su parte, los alemanes insisten en la misma idea de que la inmunidad es un privilegio del Parlamento y no de los diputados ${ }^{12}$.

9 Gabino Bugallal, en defensa de esta tesis, afirma que la prerrogativa no es un don, o gracia, o excepción de la ley común, «sino la determinación de condiciones especiales que una persona $\mathrm{u}$ organismo necesita para realizar una misión pública o social, impuesta o reconocida por la misma ley»; Inviolabilidad parlamentaria, public. de la Real Academia de Ciencias Morales y Políticas, Madrid, 1921, pág. 9.

${ }_{10}$ Ferrara, Trattato, t. I, pág. 86.

${ }^{11}$ F. J. Wright, British Constitution and Government, MacDonald and Evans, Londres, 1973, pág. 22. También el clásico T. Erskine May, Treatise on the Law, Privileges, Proceedings, and Usage of Parliament, 19. ${ }^{2}$ ed., Londres, 1976, afirma que «los privilegios del Parlamento son derechos que son absolutamente necesarios para el debido cumplimiento de sus funciones» (pág. 67).

${ }_{12}$ Theodor Maunz, «Die Immunität ist ein Vorrecht des Bundestages, nicht ein Recht des Abgeordneten», en Deutsches Staatsrecht, 3. ${ }^{2}$ ed., pág. 236. Véase también Hatschek, Deutscbes und Preussiscbes Staatsrecht, I, Berlín, 1930, págs. 528 y sigs. 
Los latinos preferimos hablar de prerrogativas ${ }^{13}$, aunque más apegados a la persona del parlamentario que a la institución del Parlamento. Es de destacar el significativo sentido subjetivo de nuestra Constitución cuando determina que los senadores y diputados «gozarán» de inviolabilidad y que «gozarán» asimismo de inmunidad ${ }^{14}$.

En conclusión, la inmunidad es una prerrogativa o atributo de la función institucional del Parlamento y de sus miembros. Por razones históricas, tampoco importa demasiado configurar a la inmunidad como un privilegio del Parlamento. Lo que en manera alguna tiene defensa es considerar actualmente a la inmunidad como un privilegio de los parlamentarios, ni siquiera como un derecho subjetivo privativo de los mismos, aunque se aleguen razones históricas válidas, pero que en muchas ocasiones han sido desnaturalizaciones poco defendibles.

\section{ORIGEN HISTORICO}

El origen remoto de la inmunidad puede hallarse en los privilegios estamentales y aristocráticos, que, en cuanto comportaban derecho de mando, fueron siendo absorbidos y anexionados por el Estado moderno y transformados en poderes o prerrogativas de los Parlamentos y de sus miembros.

Los estamentos de la nobleza y clero mantuvieron y afirmaron sus privilegios cuando sus respectivos «brazos» se reunían en Cortes o Asamblea representativa. Por lo que respecta al «tercer estado», estamento «llano» o «común» - en terminología inglesa-, trató históricamente de alcanzar el mismo status privilegiado. La razón es que, al ser dicho estamento el más débil, luchó por sus privilegios contra la Corona, los Tribunales, y también contra la nobleza espiritual y temporal hasta que logró verlos reconocidos por la Ley ${ }^{15}$.

El primer privilegio inmunitario fue concretado en la garantía para que los parlamentarios - $\mathrm{y}$ sus servidores-, sin ser molestados ni detenidos, pudieran viajar desde su domicilio hasta la sede del Parlamento, para permanecer libremente en él y para que pudieran regresar con iguales seguridades a sus casas. Es el privilegio denominado coming, remaining, and returning ${ }^{16}$.

Aunque los ingleses se remontan en precedentes al siglo XIII ${ }^{17}$, ciertamente que la inmunidad no queda claramente consolidada hasta que el Parlamento logra imponerse a la Corona en las largas pendencias del siglo xvIr, y expresamente en el Bill of Rights que los lores y los comunes hacen jurar en 1689 a los príncipes Guillermo y María de Orange como condición inexcusable para

${ }^{13}$ Véase Roberto Lucifredi, Elementos di Diritto Pubblico, 8." ed., pág. 68. Asimismo, en España, el primer Reglamento del Congreso que utiliza la idea de prerrogativa es el de 29 de noviembre de 1934 , secc. $4 .{ }^{2}$, arts. 43 y sigs., y el mismo criterio se sigue en el nuevo Reglamento del Congreso que está actualmente en vías de tramitación.

${ }_{14}$ Artículos 71.1 y 2 de la Constitución.

15 Este supuesto se dio en Inglaterra a principios del siglo xv, a través del «Chedder's case, 1404" (citado por May en su famoso Treatise on the Law, Privileges, Proceedings, and Usage of Parliament, 19." ed., Londres, 1976, pág. 69).

${ }^{16}$ Erskine May, ibíd., pág. 94 .

${ }^{17}$ May cita el Bishop of St. David's case, de 1290, y el Prior of Malton's case, de 1315. 
acceder al trono de Inglaterra, vacante por abdicación forzada de Jacobo $\mathrm{II}^{18}$.

De manera más inmediata y dogmática, la inmunidad se estableció con carácter de generalidad en Francia en la célebre sesión de la Asamblea Nacional de 28 de junio de 1789, pocos días antes de la Declaración de Derechos del Hombre y del Ciudadano. Posteriormente se recogió en la Constitución de 1791, que aplicaba con cierto ritual el principio de división de poderes ${ }^{19}$, y más tarde se confirmó la inviolabilidad en la Constitución de $1793^{20}$. Esta Constitución fue la convencional, con predominio inicial de la Asamblea Nacional, pronto absorbida por el Comité de la Salud Pública, que ejerció la dictadura y el terror, del que no se escaparon los propios diputados, a cuyo efecto se derogó la inviolabilidad en la sesión de 12 de diciembre de 1793, alegándose el interés nacional, la justicia debida al pueblo, y el sagrado principio de la igualdad, que no pueden permitir que en la investigación de la culpabilidad y en el castigo de los delitos se haga una injusta distinción entre los representantes del pueblo y cualesquiera otros ciudadanos. Pasado el terror y el 9 de Thermidor, se promulgó la Constitución Directorial de 1795, que volvió a regular la inviolabilidad con gran minuciosidad ${ }^{21}$, y desde entonces se ha mantenido constantemente en todos los textos constitucionales franceses y se expandió como una mancha de aceite a todo el Derecho constitucional contemporáneo.

Frente a muchas otras tesis justificativas, lo cierto es que originalmente el fundamento de la inmunidad estaba en la deseada garantía o seguridad que buscaban las asambleas, elegidas en precaria posición, frente a los poderosos ejecutivos que acumulaban la tradición absolutista de antaño. Se trataba en definitiva de proteger a los parlamentarios de las medidas represivas del Gobierno.

Según se fue asentando la democracia y consolidándose los Parlamentos, los temores del legișlativo al ejecutivo, e incluso al judicial, fueron desapareciendo. Paralelamente decreció el interés por la inmunidad.

En la actualidad, en países de democracia consolidada y firme arraigo del Estado de Derecho, a ningún parlamentario se le pasa por la imaginación que pueda ser objeto de una arbitrariedad gubernativa o judicial respecto a su libertad personal. Sin embargo, los Parlamentos, celosos veladores de

18 El Bill of Rights contiene fundamentalmente trece derechos y libertades que el Parlamento desea dejar bien asentados frente a la Corona, y entre ellos, el que lleva el número nueve afirma: «Que la libertad de palabra y de debates o de actuaciones en el Parlamento no pueda ser impedida o puesta en cuestión ante tribunal alguno, $y$ en ningún lugar que no sea el Parlamento mismo.»

${ }_{19}$ Constitución de 3 de septiembre de 1791, en el art. 7 de la sección V, del capítulo I, del título III afirma que «los representantes de la Nación son inviolables; no podrán ser buscados, acusados, ni juzgados por lo que hayan dicho, escrito o hecho en el ejercicio de sus funciones de representantes», y seguidamente en el attículo 8 establece el requisito de la previa autorización del Cuerpo legislativo para proceder en ciertos casos contra dichos representantes.

${ }_{20}$ Constitución de 24 de junio de 1793 ; en sus artículos 43 y 44 se reproducen casi literalmente los textos de los preceptos de 1791.

${ }^{21} \mathrm{La}$ Constitución de 5 Fructidor del año III (22-VIII-1795) reguló las garantías personales de los miembros del Consejo de Ancianos y del Consejo de los Quinientos en los catorce artículos que van del 110 hasta el 123. 
sus usos y tradiciones, han seguido manteniendo la prerrogativa, basándola en nuevas ideas y fundamentos.

\section{INMUNIDAD E INVIOLABILIDAD.}

La inviolabilidad (o irresponsabilidad) es la prerrogativa esencial del Parlamento y de los parlamentarios. Consiste en que dentro de la Cámara, y en el ejercicio de las funciones propias de la misma, la libertad de palabra es plena (freedom of speech), lo cual no deja de ser singular, porque en toda democracia correctamente asentada debe darse la libertad de expresión y de difusión de los pensamientos, ideas y opiniones ${ }^{22}$.

Ahora bien: la diferencia estriba en que mientras un particular es responsable del uso que haga de su libertad de expresión, y puede ser llevado a los tribunales por la apología que pueda haber hecho de un delito o por la pública incitación a una sedición o por simples calumnias e injurias, muy al contrario, los parlamentarios son irresponsables por cuanto digan, afirmen, voten o expliquen en el ejercicio de su función parlamentaria. Esta inviolabilidad-irresponsabilidad es absoluta y perpetua. Royer-Collard, filósofo parlamentario de la Restauración que presidía la Cámara cuando las Ordenanzas de julio de 1848, afirmaba: «La Tribuna no es justiciable más que por la Cámara» 23 .

Esta prerrogativa es esencial, pues es claro que el parlamentario en el ejercicio de su función no puede sentirse constreñido por posibles acciones de la autoridad gubernativa o judicial, ni de acciones del ministerio fiscal, ni de querellas de particulares.

En buena lógica parece como si la inmunidad fuese la salvaguarda y consecuencia inevitable de la inviolabilidad, pues, evidentemente, el hecho de que ningún parlamentario pueda ser detenido, procesado, preso ni enjuiciado sin previa autorización de la Cámara supone prima facie una garantía o defensa de la inviolabilidad ${ }^{24}$, y en el mismo sentido, Sánchez Román aducía que «la inmunidad parlamentaria es un corolario de la inviolabilidad, un complemento necesario y una manera de hacerla efectiva ${ }^{25}$.

Sin embargo, la inmunidad no es sólo una garantía de la inviolabilidad, sino cuestión bien distinta.

Primero, la inviolabilidad ampara al parlamentario dentro de la Cámara, mientras que la inmunidad lo protege por acciones realizadas fuera de sus muros.

Por otra parte, el Tribunal ante el que se plantee una acción pública o privada contra un parlamentario con ocasión de un acto realizado en el ejercicio

${ }^{22}$ Artículos 16.1 y 20.1 de la Constitución.

${ }^{23}$ Citado por J. Barthélemy, Précis de Droit Constitutionnel, Dalloz, 1936, pág. 293.

${ }^{24} \mathrm{La}$ conferencia fue pronunciada en el Círculo Conservador de Zaragoza el 26 de no viembre de 1911, y su título era «Inviolabilidad e inmunidad parlamentarias», fue publicada por Retes, Madrid, 1912.

${ }_{25}$ Dictamen del fiscal del Tribunal Supremo, D.F.S.R., con motivo de la consulta formulada por Real Orden de 26 de octubre de 1898 (Madrid, 1898, pág. 5). 
de su función debe declararse incompetente en virtud de la prerrogativa de inviolabilidad. En cambio, el Tribunal ante el que se interponga una acción contra un parlamentario con ocasión de una acción u omisión realizada fuera de su función - como cualquier otro ciudadano- debe solicitar el suplicatorio o autorización al Parlamento para procesar o continuar el juicio.

En ambos supuestos se trata de causas justificativas que excluyen de la pena ${ }^{26}$, pero que en la inviolabilidad actúa ope legis, mientras que en la inmunidad opera sólo si se deniega el suplicatorio o autorización por el Parlamento. En el primer caso es evidente que sólo se pretende salvaguardar la función parlamentaria, y por eso el diputado no puede renunciar a la inviolabilidad; mientras que en el segundo caso puede también estarse garantizando un interés privativo del diputado y, por tanto, se admite su renuncia, aunque algún sector doctrinal mantenga lo contrario ${ }^{27}$.

Cierto que cuando un Tribunal comienza sus actuaciones puede no conocer con exactitud las circunstancias del caso, y la alegación de la inmunidad y el subsiguiente suplicatorio podría ser la vía para constreñir la inviolabilidad. Pero este supuesto es utópico, puesto que la inviolabilidad está bajo la salvaguardia del Reglamento de la Cámara y de su presidente, que lo aplica.

En realidad, cuantos pretenden fundamentar la inmunidad como algo accesorio y derivado de la inviolabilidad, lo que en verdad intentan es empequeñecer la inmunidad y restarle legitimidad, en lo que no deja de haber cierto sentido de razón por lo que su uso en nuestra patria ha tenido de abusivo, privilegiado e injusto.

\section{OTRAS JUSTIFICACIONES}

En realidad, la inmunidad no tiene otra fundamentación sólida que la histórica ya reseñada. Pero no puede dejarse de aludir a otras muchas justificaciones que en su favor ha realizado la doctrina y cuyo repaso sirve para perfilar la institución.

Santi Romano fundamenta la inmunidad en el principio «de la independencia y de la autonomía de las Cámaras frente a los demás órganos y poderes del Estado» ${ }^{28}$. Viene a ser una traducción práctica del principio de la división de poderes de Montesquieu, en cuya virtud, si los miembros del poder legislativo pudieran ser detenidos por el ejecutivo o procesados por el judicial, se produciría una intromisión inadmisible en la independencia debida a la Cámara legislativa ${ }^{29}$.

A la misma conclusión llega la tesis de que la inmunidad es un resultado

${ }^{26}$ Rodríguez Devesa, Derecbo penal, t. I, Madrid, 1970, pág. 541.

27 Concretamente, el Tribunal de Bourges sentenció el 14 de mayo de 1927 que la inmunidad no puede ser renunciada, porque es cuestión de orden público que escapa al arbitrio del parlamentario (citado por Barthélemy, Précis de Droit Constitutionnel, París, 1936, pág. 299).

${ }_{28}$ Corso de Diritto Costituzionale, Padua, 1931, pág. 247. Véase también Lojacono, Le prerrogative dei membri del Parlamento, Milán, 1954, págs. 22 y sigs.

${ }_{29}$ Véase Miceli, Immunità parlamentari, en «Enc. Giur. it.», VIII, pt. I, 1902, págs. 110 y sigs. 
de la soberanía del Parlamento. Es decir, la inmunidad es una cualidad inseparable del órgano soberano. Habida cuenta que la soberanía reside en el pueblo y éste la ejerce a través de sus representantes en el Parlamento, parece como que cualquier ataque a la libertad personal de cada uno de éstos supusiese una vulneración del órgano soberano, que por sus propias esencias debe ser inviolable. Pero esto, que es cierto en cuanto al órgano, ya no lo es tanto en cuanto a los miembros que lo integran, porque, como afirma Orlando, «el disminuir un miembro en la misma no impide que la Asamblea continúe funcionando normalmente; el caso puede ocurrir incluso por muerte, dimisión, anulamiento de la elección, etc.» ${ }^{30}$.

Parecida fundamentación es la de Rossi, que basa la inmunidad en la necesidad de asegurar el mutuo respeto constitucional de los órganos del Estado, derivada de la autonomía especial de cada uno en el ejercicio de sus funciones ${ }^{31}$. En realidad, las razones justificativas con unos u otros matices pueden multiplicarse, y no vienen a ser, en conjunto, más que legitimaciones de poder, de prerrogativas, o de funcionalidad del órgano.

Pero sería injusto no hacer también referencia a otras posiciones de orden práctico y más subjetivo. Tal es el caso de aquellos que amparan la inmunidad en una garantía del parlamentarismo frente a una presión o venganza que pueda ejercerse bajo forma de una persecución penal por parte del Gobierno o de particulares. Bugallal afirma en este sentido que la inmunidad «es necesaria para que la pasión política o la intriga de los particulares no arranque al senador o diputado de su asiento en la Cámara durante un período de sesiones y so pretexto de infracciones punibles maliciosamente perseguidas» ${ }^{32}$. Análogo fundamento es el de quienes afirman que el alto oficio parlamentario no debe ser perturbado sin causa proporcionada, sobre todo si son faltas innocuas y de poca monta. Finalmente, hay quien trata de fundamentar la inmunidad en la libertad de tribuna, en la independencia del representante del pueblo, en el respeto al elector en algunos casos, cuando no en la libertad de voto.

La realidad es que cuantas justificaciones se aducen tratan de encontrar la base doctrinal de un puro hecho histórico, que consiste en defender a las Cámaras legislativas y sus miembros de la prepotencia clásica del ejecutivo. También se da la circunstancia de que los diputados y senadores se resisten a renunciar a una prerrogativa «que ha aprovechado ampliamente a los que les precedieron» ${ }^{33}$.

De todo ello se infiere que la justificación teórica y doctrinal de la inmunidad es sumamente débil. De ahí que prosperen con cierta razón tesis de abierta oposición a su mantenimiento, como fue el caso de Kelsen, que entendía al régimen parlamentario como un sistema en que el Gobierno no es otra cosa que una especie de comisión del Parlamento que está sometida al riguroso

${ }^{30}$ Orlando, Immunità parlamentari ed organi sovrani (a proposito del caso di un giudizio d'interdizione contro un membro del Parlamento), «Riv. de Diritto Pubblico e della Pubblica Amministrazione in Italia», Roma, 1933, XII, pág. 34.

${ }^{31}$ Rossi, La immunità dei deputati, en «Arch. Giur.», 1897, LVIII, págs. 235 y sigs.

32 Op. cit., pág. 11.

${ }^{33}$ F. Silvela, op. cit., pág. 49. 
control de la oposición y de la opinión pública ${ }^{34}$. Se da además el riesgo - hasta ahora poco usual- de que las mayorías parlamentarias impongan su arbitrio al otorgar suplicatorios que no estarían dispuestos a otorgar para sí mismos.

En conclusión, la inmunidad es una institución histórica que ha cumplido su función y que en la actualidad subsiste por inercia de la tradición. En las democracias bien asentadas es una prerrogativa en desuso, pues la institución parlamentaria se halla bien salvaguardada por el arraigo de sus usos y funcionamiento. Es significativo al respecto el precedente del proceso de Mr. Creasury, que, habiendo hecho insertar en un periódico de Londres un discurso en el que se contenían injurias a una persona, fue condenado por libelo a pagar la multa de cien libras, sin que para ello se pidiese autorización a la Cámara, que, por otra parte, declaró que en esa condena no había infracción de sus privilegios ${ }^{35}$.

Más significativo fue el caso de Lord Cochrane, que, siendo miembro de la Cámara de los Comunes en 1815, fue procesado y preso por presunto delito de conspiración. Logró escapar de la prisión y fue detenido de nuevo cuando estaba aposentado en su banco del salón de sesiones en Westminster. En este supuesto, y contra todo lo que hubiera sido considerado natural en los países latinos, el Comité de Privilegios de la Cámara de los Comunes dictaminó que no se habían violado los privilegios del Parlamento, y el clásico tratadista E. May corrobora: «He aquí cómo la Cámara no permite que ni siquiera el santuario de sus muros proteja a un miembro contra el Derecho penal» ${ }^{36}$.

\section{INMUNIDAD EN LAS CORTES DE CADIZ}

Durante los tres siglos que preceden a la época constitucional, las Cortes apenas celebraron reuniones, si bien la Novísima Recopilación determinaba que los procuradores no podían ser demandados ante la justicia durante el ejercicio de sus funciones ${ }^{37}$.

Este residuo histórico es recogido por el Reglamento de las Cortes de 1810, que en las causas criminales sometía a los diputados al fuero especial de las propias Cortes constituidas en Tribunal, y en las causas civiles estaban exentos ante cualquier acción que se interpusiera durante el tiempo del mandato y un año más después de concluido ${ }^{38}$. Esta posición es recogida por la Constitución de Cádiz, si bien reduciendo la franquía de los diputados en las causas civiles y ejecución por deudas al período de sesiones «y un mes después» ${ }^{39}$. En cuanto a la regulación de la jurisdicción de las Cortes para enjuiciar las denuncias y

${ }^{34}$ La Démocratie, sa nature, sa valeur, trad. francesa de Eisennmann, París, 1932, página 51.

${ }_{35}$ Citado por F. Silvela, La inmunidad parlamentaria, en «Rev. de Legislación y Jurisprudencia», año XXXVIII, tomo 76, págs. 32 y sigs.

${ }_{36} \mathrm{Ob}$. cit., libro I, cap. V, pág. 105.

${ }^{37}$ Ley $V$, tít. 8. ${ }^{\circ}$ libro $3 .^{\circ}$ de la Novísima Recopilación.

${ }^{38}$ Reglamento para el gobierno interior de las Cortes aprobado en sesión de 27 de noviembre de 1910 , cap. IV, arts. 4 a 8.

${ }^{39}$ Constitución de 19 de marzo de 1812, art. 128. 
delitos contra sus diputados, se halla minuciosamente recogida en los Reglamentos de $1813^{40}$ y de $1821^{41}$.

El Estatuto Real reconoció sólo la inviolabilidad de próceres y procuradores, pero no hizo mención expresa de la inmunidad ${ }^{42}$, que, no obstante, se acreditó por vía reglamentaria, otorgando a las Cortes la facultad de juzgar a sus miembros, siguiendo en este punto la tradición de $1812^{43}$.

Finalmente, esta fase se cierra con el Proyecto Istúriz, que mantenía para los próceres su sumisión jurisdiccional a la propia Cámara ${ }^{44}$.

El resultado más notorio de la inmunidad en el aspecto civil fue un privilegio exorbitante. En cuanto a la acción penal, la condición de diputado constituyó una verdadera carta de impunidad. Por excepción, cuando las acciones de los diputados afectaban a la propia institución legisladora, la inmunidad pasó a ser un privilegio odioso y perjudicial.

Tal fue el caso de la sesión de 3 de febrero de 1814, que, con ocasión de discutirse las formalidades que habían de observarse con motivo del regreso a España de Fernando VII - tras cerca de seis años de destierro en Francia-, el diputado López Reina expuso la idea de que, habiendo recibido el rey la soberanía absoluta de su padre Carlos IV, era indispensable reintegrársela tan pronto pisara la raya de la frontera. Estas palabras fueron consideradas subversivas, y a pesar de la inviolabilidad reconocida por el artículo 128 de la Constitución, una gran mayoría votó a favor de que se abriese causa al diputado López Reina ${ }^{45}$, con lo que se quebrantó el privilegio parlamentario.

Más grave y significativa, por su carácter retroactivo, fue la resolución infamante que al inicio del trienio liberal (1820) adoptaron las Cortes contra los sesenta y nueve diputados que firmaron el famoso manifiesto y representación que, dirigido a Fernando VII el 12 de abril de 1814, comenzaba con la siguiente frase: «Era costumbre en los antiguos persas pasar cinco días en anarquía después del fallecimiento de su rey, a fin de que la experiencia de los asesinatos, robos y otras desgracias les obligase a ser más fieles a su sucesor...» Pues bien: las Cortes, en Decreto de 26 de octubre de 1820 acordado tras importante debate, liberó a dichos diputados de la formación de causa (aunque mandó detenerlos), pero con la condición de que perdieran todos los empleos, honores, condecoraciones; y se declara expresamente que «han perdido la confianza de la nación» ${ }^{46}$.

40 Reglamento de las Cortes de 4 de septiembre de 1813, arts. 52 a 62.

${ }^{41}$ Reglamento del gobierno interior de las Cortes y su edificio de 29 de junio de 1821 , artículos 54 a 67 .

${ }_{42}$ Artículo 49 del Estatuto Real de 10 de septiembre de 1834

${ }^{43}$ El Reglamento del Estamento de Procuradores de 15 de julio de 1834 atribuye funciones judiciales al propio Estamento para juzgar «a sus propios individuos, ya sea por delitos comunes que cometan durante el tiempo de su mandato, ya por faltas o abusos en que puedan incurrir como tales procuradores» (art. 139.2).

44 El Proyecto Istúriz de 20 de julio de 1836 no prosperó como consecuencia del motín o sargentada de La Granja que restableció la vigencia de la Constitución de 1812; pero en dicho proyecto se mantenían las facultades judiciales del Estamento de Próceres para juzgar a sus miembros (art. 20.3), mientras que para los diputados se hacía remisión a una ley especial (art. 23).

${ }_{45}$ Inviolabilidad e inmunidad parlamentarias Congreso-Senado 1810, 1911, publicado por la Secretaría del Congreso de los Diputados, Madrid, 1912, págs. 55 a 59.

46 Ibíd., págs. 73 a 150. 


\section{INMUNIDAD EN LA MONARQUIA CONSTITUCIONAL}

Durante la primera guerra carlista, los liberales abolieron la jurisdicción de las Cortes sobre sus diputados y establecieron en la Constitución de 1837 el sistema ya clásico de la previa autorización de la Cámara para las detenciones y procesamientos de sus miembros. La experiencia anterior no había sido satisfactoria y se prefirió que los parlamentarios se sometieran a la jurisdicción ordinaria, con la condición de que ninguna actuación pudiese prosperar sin la necesaria y oportuna autorización del Parlamento, salvo la excepción del flagrante delito.

El punto de inflexión lo marca la Constitución orleanista de 1830 , que mantiene para los pares su tradicional jurisdicción autónoma ${ }^{47}$, pero a los diputados se les somete al trámite del suplicatorio y previa autorización de la Cámara para poderlos detener y procesar ${ }^{48}$.

Este nuevo sistema ha causado estado de perdurabilidad, pues en sustancia sigue siendo el mismo que prevaleció a través de todos los regímenes hasta la actualidad ${ }^{49}$.

Durante el siglo XIX se consagró la inmunidad parlamentaria en forma muy similar en las Constituciones progresista de 1837 , moderada de 1845 , revolucionaria de 1869 , proyecto republicano de 1873 y la restauradora de $1876^{50}$. Los Reglamentos de las Cámaras recogieron todos ellos la regulación de la inmunidad en forma muy laxa y discrecional, de manera que el Congreso tenía la facultad de resolver lo que estimase «oportuno» en cuantos casos se le presentasen ${ }^{51}$. Sólo a principios dèl siglo actual se adoptaron criterios más reglados en la Ley especial de 9 de febrero de 1912 y en el Reglamento del Congreso de 24 de mayo de $1918^{52}$.

Lo ocurrido en la realidad durante los casi cien años de monarquía cons-

${ }^{47}$ Artículo 29 de la Constitución francesa liberal de 14 de agosto de 1830.

${ }^{48} I$ Ibíd., art. 44, que viene a ser una rectificación del criterio precedente mantenido por la Carta otorgada de Luis XVIII en 1814 (arts. 33 y 34).

${ }_{49}$ Cabe aducir como única excepción el Reglamento de la Asamblea Nacional de 20 de septiembre de 1927, que pasa por alto la regulación de los privilegios o prerrogativas parlamentarias.

${ }_{50}$ Artículo 42 de la Constitución de 18 de junio de 1837; art. 41 de la Constitución de 23 de mayo de 1845; art. 56 de la Constitución de 1 de junio de 1869 (véase, en especial, A. Carro, La Constitución española de 1869, Madrid, 1952, pág. 296); art. 77 del Proyecto constitucional de 1873 y art. 47 de la Constitución de 30 de junio de 1876.

${ }^{51}$ El Reglamento del Congreso más duradero fue el del 4 de mayo de 1847 (con las modificaciones introducidas en 18-VI-1864, 16-XII-1878, 7-IV-1880, 10-IV-1883, 18-VI1887, 7-IV-1894, 23-II-1895 y 24-VII-1896), y recogió el principio de inmunidad en su artículo 207 en fórmula muy simple y escueta, en el sentido de otorgar a la Cámara facultades absolutamente discrecionales para otorgar la autorización para detener y procesar a los diputados, con el único requisito de que había de ser oída una comisión parlamentaria designada al efecto. Este artículo 207 fue copiado del art. 139 del Reglamento de 14 de febrero de 1838 , y posteriormente reproducido con escasas variaciones por los Reglamentos del Congreso de 1 de diciembre de 1854 (art. 32); de 25 de junio de 1867 (artículo 223), y de 5 de agosto de 1873 (art. 247).

${ }_{52}$ El Reglamento del Congreso de 25 de mayo de 1918 es el primero que regula un minucioso procedimiento en relación con la inmunidad y los suplicatorios (arts. 133 a 137). 
titucional es variopinto y merece un análisis pormenorizado. Por el momento, valga destacar que la inmunidad no fue en España un privilegio útil contra el ejecutivo, pues Azcárate, en las sesiones que culminaron con el acuerdo de 12 de julio de 1904, afirmaba que «en setenta años de régimen parlamentario y constitucional en España no conocía ni un solo caso en que ningún Gobierno haya estorbado a ningún diputado en su acción» ${ }^{53}$, lo que no impidió que el Congreso, en aquella misma sesión, denegase en bloque 178 suplicatorios pendientes.

Un estimable trabajo realizado por la Secretaría del Congreso de los Diputados ${ }^{54}$ permite recomponer la siguiente estadística. Durante el siglo que va de 1810 a 1911 se recibieron en el Congreso unos 1.277 suplicatorios, de los que 469 recibieron denegación expresa, 219 fueron desistidos, 544 no se resolvieron y sólo 45 fueron concedidos. Esto significa que sólo se otorgó alrededor de un 3 por 100 de los suplicatorios, mientras que el 97 por 100 restante produjo efectos negativos entre denegados, desistidos y no resueltos ${ }^{55}$.

Más desequilibrada resulta la proporción si se para atención en que veintiocho de las cuarenta y cinco concesiones se hicieron con carácter excepcional y en bloque. En efecto, en las Cortes Constituyentes de 1869, el presidente del Gobierno Prim (que tenía en su haber de parlamentario bastantes suplicatorios no concedidos) propuso y obtuvo autorización de las Cortes para que los Tribunales pudieran proceder contra los diputados que apareciesen complicados en el delito de rebelión, a cuyo amparo se procesaron once diputados, respecto de los cuales los Tribunales comunicaron la sentencia a las Cortes y éstas dictaminaron con la fórmula de «las Cortes quedan enteradas» ${ }^{56}$. El segundo caso se dio en las Cortes Constituyentes de la I República, que tras censurar a los diputados que se alzaron en armas contra ellas, acordaron excitar el celo de la autoridad competente para que pidan el suplicatorio, «en la seguridad de que jamás podrán consentir que se violen las leyes», y, en efecto, se concedieron de esta forma hasta diecisiete suplicatorios. Otros suplicatorios concedidos por la idea de rebelión o atentado militar correspondieron a los generales Narváez y Fernández de Córdova en 1838 y Azpiroz en 1841, a don Lorenzo Calvo Mateo por intento de asesinato a Narváez en 1843, al señor

${ }^{53}$ Véase Bugallal, op. cit.

${ }^{54}$ Inviolabilidad $e$ inmunidad parlamentarias, 1810-1911, tomo II, Madrid, 1912, páginas 637 y sigs.

${ }_{55}$ No concuerda esta estadística con la que facilita Silvela en su citado trabajo en la «Revista de Legislación y Jurisprudencia», año XXXVIII, tomo 76, en donde afirma que de «los datos que ofrece el archivo del Congreso a contar desde 1837, resultan ciento cincuenta y nueve autorizaciones solicitadas por los Tribunales de Justicia, y de ellos sólo veintitrés concedidas, figurando entre las negadas cuantas se solicitaron por delitos de injurias, desacato a la autoridad, delitos electorales, responsabilidad de los gobernadores por detenciones arbitrarias; sesenta y cuatro por rebelión y sedición, dos por asesinato, dos por defraudación a la Hacienda; cuatro por daños causados por empresas industriales, y dos por quebrantamiento de condenas (pág. 49). Pero es evidente que esta documentación facilitada por Silvela es incompleta.

${ }_{56}$ Se trataba fundamentalmente de diputados republicanos que se habían rebelado, como era el caso de Gonzalo Serraclara, que había sido hecho prisionero en las barricadas de Barcelona; el mismo caso era el del general Pierrad. Excepcionalmente se encontraban en este paquete de suplicatorios los de los diputados navarros Ochoa y Zabala, por conspiración carlista. 
de Reboreda por su proclama incitando a la rebelión de Galicia (1848) y a Roque Barcia por el presunto delito de asesinato a Prim (1871). Algunos suplicatorios se concedieron por apropiación indebida o desfalco, como los casos de Ramírez de Arellano (1838), Fagoaga (1848) y Yáñez Rivadeneira (1861) ${ }^{57}$.

No hay duda de que en todos estos casos la inmunidad no amparó conductas delictivas de los parlamentarios. Pero ¿qué decir del millar largo de suplicatorios expresa o tácitamente denegados? Cierta explicación, ya que no justificación, podrían encontrar los muchos suplicatorios denegados por tratarse de delitos de imprenta, de injurias o electorales, habida cuenta de la pasión que suele acompañar a este tipo de acciones, y que en muchos casos habrían dado lugar a sentencias absolutorias. Ninguna explicación objetiva tiene la denegación en 1869 del suplicatorio contra Jacinto Anglada por haber matado en duelo a Celestino Olózaga, y parecido fue el caso del duelo entre Ríos Rosas y González Bravo en 1850. Más que negligentes pueden ser calificadas las Cortes de 1870, que no dictaminaron diecisiete suplicatorios contra Paúl y Angulo, que pocos meses después se vería envuelto como presunto implicado en el asesinato de Prim.

En cambio, nuestra historia está salpicada de flagrantes violaciones de la inmunidad, como cuando en el tránsito de 1866 a 1867 son detenidos, entre otros, nada menos que el presidente del Congreso, Ríos Rosas, y el presidente del Senado, general Serrano.

La conclusión es que la inmunidad no siempre servía para lo que debía servir, y cuando fue utilizada era frecuentemente con abuso de quienes debían ser ejemplo de conducta y de ciudadanía.

Al comienzo del siglo actual se intentó remediar esta situación. A este efecto, en 30 de octubre de 1903, el presidente del Congreso sometió a la consideración de la Cámara el hecho de que existía gran número de suplicatorios pendientes, con la subsiguiente paralización de los Tribunales. En su consecuencia, se acordó constituir una comisión especial que los dictaminase, y así lo hizo respecto a casi setenta suplicatorios despachados en sentido denegatorio. La mayor parte de ellos se refería a delitos de imprenta, encontrándose entre los implicados Vázquez de Mella, Lerroux; Blasco Ibáñez, Víctor Pradera, Nicolás Salmerón, etc. ${ }^{58}$.

A raíz de este trabajo se acordó modificar el Reglamento de la Cámara en el sentido de constituir una Comisión Permanente de Suplicatorios y modificar el tradicional silencio de sentido negativo por el acuerdo contrario. Es decir, que el silencio durante treinta sesiones públicas siguientes al día de en-

${ }^{7}$ En 1896 se concedieron cuatro suplicatorios de análoga naturaleza. Tres, referentes al mismo diputado, y todos ellos por presuntos delitos de fraude y de prevaricación.

${ }^{58}$ En dicha Comisión se despacharon con dictamen denegatorio por delitos de imprenta respecto de los siguientes diputados: Ádolfo Suárez de Figueroa (quince suplicatorios), Juan Vázquez de Mella (trece), Diego Fernández Arias (nueve), Alejandro Lerroux (ocho), Vicente Blasco Ibáñez (cuatro), Víctor Pradera (tres), Vicente Onalde (tres), Angel María Carvajal (dos) y un solo suplicatorio para cada uno de los que siguen: Antonio González López, Baldomero Lostau, conde de Benalúa, Nicolás Salmerón, Nougués, Lombardero, Moya y Junoy. Por presuntos delitos de injuria se denegaron sendos suplicatorios contra Salmerón y Marenco, y por imputaciones contra la forma de gobierno, se denegó uno, referente a José Muro. 
trada del suplicatorio debía interpretarse como equivalente a su concesión, y así quedar expedita la vía judicial.

La Comisión Permanente de Suplicatorios quedó constituida en 11 de julio de 1904 por Dato, Marqués de Vadillo, González Besada, García Alix, Canalejas, Lloréns, Romanones y Azcárate, y al día siguiente adoptan el acuerdo de no autorizar en bloque ciento setenta y ocho suplicatorios pendientes. Al reanudarse las sesiones, en octubre de 1904, y tras casi un mes de debates, se denegaron otros veintisiete suplicatorios. La tesis mantenida era que, frente $a$ un antiguo régimen de impunidad, iban a entrar en otro de severidad, $y$ buen avance era que se produjeran pronunciamientos expresos contra la costumbre del silencio inmunizador.

Como consecuencia de lo anterior, se presentó un proyecto de ley sobre tramitación de suplicatorios que fue debatido durante todo el año 1904, pero los grupos no se pusieron de acuerdo, y cuando las Cortes se disolvieron, ningún texto se había aprobado.

Romanones presenta otro proyecto análogo en 1906, que tampoco prosperó y que significó un nuevo aplazamiento de la aplicación del silencio positivo del acuerdo de 9 de julio de 1904. En la sesión de 28 de abril de 1909, Romanones hace notar que la cuestión de los suplicatorios se ha agravado sensiblemente después del acuerdo de 1904, puesto que antes se concedió excepcionalmente algún suplicatorio, pero desde entonces no se había concedido ninguno, ni se había dado ningún dictamen.

Por fin, en 10 de marzo de 1911, el ministro de Gracia y Justicia Ruiz Vilarino presenta un nuevo proyecto de ley que, tras muchas vicisitudes, pasó a ser la Ley de 9 de julio de 1912, que aún es hoy derecho vigente en materia de suplicatorios y cuya finalidad esencial estriba en que los parlamentarios son aforados ante la jurisdicción del Tribunal Supremo ${ }^{59}$.

En esta legislatura de 1911-14 se bate todo un récord, concediéndose treinta y ocho autorizaciones para procesar referentes a otros tantos suplicatorios, relativos la mayor parte a delitos de imprenta. Pero es de notar que en tal momento había remansados más de cuatrocientos suplicatorios en la correspondiente comisión.

En las legislaturas sucesivas de la monarquía sigue gravitando la misma tónica de incremento de suplicatorios ingresados y casi ninguno concedido.

La conclusión es que la impunidad que históricamente ha cubierto la inmunidad parlamentaria ha sido muy amplia y casi nunca bien justificada, aunque es preciso resaltar que la gran mayoría de los suplicatorios se refería a artículos sueltos y caricaturas publicadas en la prensa o a presuntas injurias y calumnias expresadas en conferencias, mítines y reuniones políticas.

${ }^{59}$ La causa de esta Ley era que el art. 47 de la Constitución de 1876 atribuía al Tribunal Supremo jurisdicción sobre los parlamentarios, pero la ulterior Ley de Enjuiciamiento Criminal (arts. 750-756), prescindió de dicha jurisdicción, haciéndose práctica usual que cualquier juzgado pudiera dirigirse en solicitud de suplicatorio, y a este estado de cosas puso fin la Ley de 9 de febrero de 1912 en orden a la jurisdicción y manera de proceder contra senadores y diputados por razón de delito. 


\section{II REPUBLICA}

La inmunidad a lo largo de la II República reviste caracteres muy similares a los de la época anterior, pero con la nota característica de que el halo de una mayor libertad y el hecho de más duras confrontaciones políticas produce el efecto de ser la época en que se baten todos los récords en cuanto a número de suplicatorios tramitados.

La Constitución republicana mantiene la tradición de que los diputados sólo pueden ser detenidos en caso de flagrante delito, lo que deberá ser comunicado inmediatamente a la Cámara. A su vez, para el procesamiento de los diputados se exige previa autorización de la Cámara, que se presumirá denegada por el transcurso de sesenta días sin contestación. Finalmente, el Congreso podrá acordar que el juez suspenda el procedimiento hasta la expiración del mandato del diputado o incluso puede dejar sin efecto cualquier detención o procesamiento de un diputado ${ }^{60}$.

El Reglamento provisional de las Cortes Constituyentes, a pesar de ser anterior a la Constitución, recoge en esencia la posición que ulteriormente pasaría al texto fundamental, con breves añadidos en lo referente a la Comisión de Suplicatorios y al debate ante el Pleno con dos turnos a favor y dos en contra ${ }^{61}$. En cuanto al Reglamento definitivo del Congreso, no hace sino confirmar las anteriores normas con mayor exactitud ${ }^{62}$.

Por lo que se refiere a la aplicación práctica de dichas normas, debe destacarse que durante las Cortes Constituyentes (1931-33) se presentaron algo más de cien peticiones de suplicatorios, siendo denegados noventa y seis por tratarse en gran medida de imputaciones delictivas cometidas a través de la prensa ${ }^{63}$. Una veintena de suplicatorios fue denegada por injurias, desacatos, frases pronunciadas en reuniones y mítines y rotura de urnas electorales. Finalmente, deben destacarse tres suplicatorios denegados, referentes a García Hidalgo, por disparos, lesiones y desacatos; y dos suplicatorios relativos a Ramón Franco por los sucesos de Tablada y por un telegrama dirigido al ministro de la Guerra, que fueron igualmente denegados.

Sólo se otorgaron durante dicha legislatura tres suplicatorios. El primero, referente a José Calvo Sotelo y Juan March, en razón de responsabilidades por el advenimiento de la Dictadura del general Primo de Rivera en 1923. El segundo, relativo a Oriol, por exportación de valores al extranjero, siendo de resaltar que el dictamen de la Comisión era denegatorio, pero ciertos votos particulares hacen que prospere la tesis contraria en el debate plenario y secreto. Finalmente, el tercero es de Bordás, que se concede por presunta mal-

*0 Artículo 56 de la Constitución de 9 de diciembre de 1931.

${ }^{61}$ Artículo 26 del Reglamento de las Cortes Constituyentes de 18 de julio de 1931.

${ }_{62}$ Artículos 44 y $45 \cdot$ del Reglamento del Congreso de 24 de noviembre de 1934.

${ }_{63}$ Destacan entre los que acumulaban más de un suplicatorio por dicho motivo los diputados Eguileor (once suplicatorios), Bariobero (siete), Balbontín (seis), García Prieto (seis), García Hidalgo (cinco), Lamamié (cuatro), Margarita Nelken (cuatro), Robles Aranguiz (cuatro). Tres suplicatorios acumularon Aguirre, Albar, Company, Semblancat, Sediles y Vázquez Campos. Sólo dos suplicatorios tuvieron acreditados Urquijo, Oreja, Morón, Leizaola y Beade. 
versación de caudales públicos ante el Juzgado de Figueras, que finaliza con el sobreseimiento.

En la legislatura 1933-1935 se tramitaron 386 suplicatorios, de los que fueron concedidos 25 , se denegaron 358 y no se dictaminaron 3 . El hecho de que se concediera más de un 6 por 100 de los suplicatorios tramitados fue una notable excepción al uso parlamentario español, pero que tiene su explicación en los graves sucesos revolucionarios de Asturias y de Cataluña. En conclusión, son veinte los suplicatorios concedidos por rebelión o requerimiento de jurisdicción militar ${ }^{64}$, cuatro suplicatorios son concedidos por presuntos delitos de prensa ${ }^{65}$, lo que constituye excepción frente a las muchas docenas de suplicatorios denegados por tal motivo, y finalmente están dos suplicatorios otorgados para procesar por tenencia ilícita de armas y por ocupación de armas de fuego ${ }^{6}$.

La legislatura de 1936 se cierra a los cuatro meses con la más flagrante violación de la inmunidad que registra la historia parlamentaria española, consistente en la detención y asesinato por fuerzas del orden gubernativo de un diputado, y que en gran medida fue la causa inmediata desencadenante de la guerra civil ${ }^{67}$. Menor trascendencia tiene que en dichos cuatro meses se tramitaran treinta y nueve suplicatorios ${ }^{68}$, referentes fundamentalmente a presuntos delitos de prensa, desacato, injurias e insultos en reuniones politicas y apología de sucesos revolucionarios, de los que se otorgaron sólo tres insoslayables: por asalto y robo en la sucursal del Banco de España en Oviedo ${ }^{69}$, por defraudación, y en relación con el entonces famoso asunto del estraperlo ${ }^{70}$.

* Los diputados a que se referían dichos suplicatorios son: Aguadé, Aguillaume, Aragay, Azaña, Bello, Billbao, Fernández Bolaños, Fernández Montes, González Peña, Hernández. Zancajo, Largo Caballero, Teodomiro Menéndez, Margarita Nelken, Prieto Tuero, Rubio Heredia, Ruiz Lecina, Santaló, Tomás Piera (dos suplicatorios) y Ventosa Roig (véase Diario de Sesiones de la Legislatura 1933-1935, núms. 119, 123, 128, 129, 140, 142, 144; $147,161,163,178,181$ у 225$)$.

${ }_{65}$ Son los suplicatorios concedidos para procesar a los diputados Negrín, Hernández Zancajo y Fernández Montes (Diario de Sesiones, núms. 181 y 187).

${ }_{66}$ Dichos suplicatorios se referían respectivamente a Lozano Ruiz y José Antonio Primo de Rivera (Diario de Sesiones, núms. 111 y 112).

67 El 10 de julio de 1936, siendo viernes, se levanta la Sesión de las Cortes con unas palabras del presidente, Martínez Barrio, fijando el Orden del Día de la Sesión inmediata para el martes, 14 de julio, pero esta Sesión ya no se celebraría, pues la víspera el diputado Calvo Sotelo había sido detenido por fuetzas del orden, apareciendo pocas horas después muerto en una vía pública. Esta violenta quiebra del principio de la inmunidad parlamentaria fue determinante de la desaparición de aquel Parlamento, produciéndose pocos días más tarde el estallido de la guerra civil.

${ }_{68} \mathrm{La}$ Legislatura perduró itinerantemente en la denominada zona republicana hasta principios de 1939 , y en esta fase precaria y de la que no se guarda documentación en la Biblioteca del Congreso, se tramitaron otra docena de suplicatorios, de los que fueron concedidos cinco.

os Estaba implicado en este suplicatorio el diputado González Peña, cuestión que venía aplazada de la Legislatura anterior (véase Diario de Sesiones de la Legislatura de 1936, número 2, pág. 14).

to Se refieren estos dos suplicatorios, respectivamente, a Carrascal y Sigfrido Blasco Ibá ñez (Diario de Sesiones, núms. 21 , pág. 14 , y 50 , pág. 1601 , ap. $5^{\circ}$ ), si bien el primero no es verdaderamente un suplicatorio, pues no siendo Carrascal diputado en esta Legislatura, la Cámara se limita a precisar que dicho señor no estaba amparado por la inmunidad. 


\section{REGIMEN AUTORITARIO}

Las Cortes Orgánicas tienen un período de vida de treinta y cuatro años (1942-1976), durante los cuales la inmunidad tuvo una vigencia singular. La Ley Reguladora de las Cortes, con rango de norma fundamental, determina que los procuradores no podrán ser detenidos sin previa autorización del presidente de la Cámara salvo en caso de flagrante delito ${ }^{71}$. Es la formulación clásica, con la nota diferenciadora de que la autorización para procesar no la otorga la Cámara, sino su presidente.

Los cuatro Reglamentos que rigieron durante esta etapa de las Cortes se limitan a regular el procedimíento de los suplicatorios ante la Comisión Permanente de la Cámara, a la preceptiva obligación de resolverlos sin dejar jugar al silencio, como ocurrió antaño con tanta frecuencia, y hacen una remisión expresa a la vigencia de la Ley de $1912^{72}$.

Es curioso que la inmunidad estuviese reconocida por la Ley de Cortes, que en materia de inviolabilidad guardaba un significativo silencio. La inviolabilidad se introdujo por vía reglamentaria, primero con cierta timidez y ya desde 1957 con la fórmula tradicional ${ }^{73}$.

El primer dato a destacar es que en esta etapa el número de suplicatorios desciende enormemente, de manera que apenas sale la media de un suplicatorio por año ${ }^{74}$. Por otra parte, se otorgan cerca del 40 por 100 de los supli-

${ }^{71}$ Artículo $5 .^{\circ}$ de la Ley Constitutiva de las Cortes, de 17 de julio de 1942, mantenido tras la modificación llevada a efecto por la Ley Orgánica del Estado de enero de 1967.

7 Artículos 7 y 8 del Reglamento provisional de las Cortes de 5 de enero de 1943. Los demás Reglamentos que sucesivamente rigieron puntualizan algo más el procedimiento, pero sin realizar modificaciones sustanciales. Así el Reglamento de las Cortes de 26 de diciembre de 1957 (arts. 7 y 8); es en este punto idéntico al que le sucedió en 22 de julio de 1967 (arts. 7 y 8). Alguna precisión mayor contiene el Reglamento de. 15 de noviembre de 1971 (arts. 9 y 10).

${ }_{73}$ En efecto, el Reglamento de 5 de enero de 1943 suple el silencio legal afirmando que los procuradores «podrán expresar libremente su opinión en sus intervenciones, sujetándose a la autoridad del presidente» (art. 6); mientras que el Reglamento de 1957 afirma inequívocamente que los procuradores «no serán responsables ante jurisdicción alguna, ni aưn después de terminado su mandato, por nínguno de los actos o manifestacioneś llevados a cabo en el ejercicio de sus funciones reglamentarias» (art. 6), y este precepto es transcrito en los Reglamentos de 1967 (art. 6) y de 1971 (art. 8). Véase en este punto a M. Fraga, Los privilegios de los procuradores y el nuevo Reglamento de las Cortes Españolas, en «Revista de Estudios Políticos», núm, 99, mayo-junio, 1958, págs. 57 y sigs. Véase también del mismo autor El Reglamento de las Cortes Españolas, Madrid, 1959, págs. 60 a 70. Véase, igualmente, M. Fraile Clivilles, Comentario al Reglamento de las Cortes, Madrid, 1973, págs. 150 a 181 .

${ }_{74} \mathrm{Al}$ resolverse los suplicatorios por el presidente de las Cortes, previa audiencia de la Comisión Permanente, no existía publicación de estos datos que han tenido que ser recompuestos a través de la documentación original existente en el Archivo del Congreso, según la cual existe constancia de haberse dictaminado treinta y siete suplicatorios durante toda la vigencia de las Cortes Orgánicas y referentes a los siguientes séñores: Lucas Moreno, Sola Domingo, Viñuela, Elías Querejeta, Rafael Pico, Nazario Díaz (dos), Salas Manzuco, Dionisio Martín, José Redondo, Eliseo Sastre, Rodríguez Eiras, J. Alfonso de Prada, Amadeo Marco, Demetrio Carceller, Villalta ( $\mathrm{y}$ dos más), Uribe, Hernández Navarro, $\mathrm{A}$. Cuevas, M. Navarro, E. Romero (dos), J. Aparicio, A. Conca, M. Valencia, España Muntadas (dos), Aníbal Arenas, G. Marañón, Socías, Llantada, Mendoza, Becerra, Ezquer, Calderón, R. Martín y Meliá. 
catorios solicitados, lo que es una reversión importante de lo que venía siendo un consenso de impunidad muy generalizada ${ }^{75}$.

$\mathrm{La}$ explicación de esta novedad estriba en que el mayor número de suplicatorios estaban motivados tradicionalmente por injurias y actuaciones relacionadas con la prensa, que en esta etapa apenas tuvieron cabida. En cambio, fueron concedidos todos los suplicatorios referidos a presuntas acciones de marcada naturaleza patrimonial, como es el caso de los referidos a delitos monetarios, Fiscalía de Tasas, falsedad, estafa, apropiación indebida, quiebra y malversación de caudales públicos ${ }^{76}$.

Dos notas deben destacarse. La primera es el uso de crear prácticamente una carta de impunidad para los procuradores en Cortes que incurrieran en delito por imprudencia en circulación rodada ${ }^{7}$, fundamentándose este hecho en su falta de gravedad, no afectar al prestigio del procurador y no haber terceros perjudicados (por estar ya satisfechas las indemnizaciones civiles exigibles), debiendo ceder estos valores «ante la conveniencia de asegurar la continuidad en el ejercicio de las funciones propias del procurador»" ${ }^{78}$.

La segunda nota fue un extravagante caso de desviación en el uso de la inmunidad, consistente en que un gobernador civil fue objeto de denuncia por torturas y sevicias y se le hizo procurador para que gozase del privilegio de inmunidad ${ }^{79}$.

La conclusión es que la inmunidad quedó muy mermada en esta etapa, pero el hecho de que se produjera también algún abuso abona la tesis de que era un privilegio en gran medida innecesario.

\section{MONARQUiA PARLAMENTARIA}

La vuelta a la democracia inorgánica después del referéndum de diciembre de 1976 no establece demasiadas variaciones en materia de inmunidad parlamentaria. Los Reglamentos provisionales del Congreso y del Senado regulan la materia en igual forma que el anterior Reglamento de las Cortes Or-

${ }^{75}$ Se otorgaton un total de catorce suplicatorios.

${ }^{76}$ Entre éstos se hallan dos suplicatorios concedidos con ocasión del muy politizado caso Matesa (uno en 4-V-1970 y otro en 23-IX-1970) en los que el informe de la ponencia contiene doctrina interesante. El suplicatorio por quiebra fraudulenta se concedió el 25 de febrero de 1969; de malversación, falsedades y estafa, es de 19 de julio de 1976; uno, por irregularidades en la gestión de la Diputación de Pontevedra es de 2 de octubre de 1952; el de comercio ilegal de arroz y falsedad de la guía de circulación que la acompañaba es de 24 de septiembre de 1949; una querella por falsedad, estafa y apropiación indebida, fue autorizada el 12 de marzo de 1948; dos, por delitos monetarios, son de julio de 1959; una infracción de disposiciones gubernativas sobre tasas fue seguida tras autorización de 7 de mayo de 1955; la imprudencia que provocó hundimiento de una central térmica, se autorizó en 22 de junio de 1964, y finalmente, se permitieron otros suplicatorios menores, relativos a disposición de bienes muebles sin debida autorización (28-X-1963), a lesiones (4-V-1955), a injurias (28-II-1974), a desobediencia y lesiones (22-VII-1972).

" Son catorce los suplicatorios denegados de esta naturaleza.

78 Esta doctrina fue sentada en los informes de la Comisión Permanente que dieron lugar a las denegaciones de los suplicatorios de 31 de octubre de 1962 y 7 de marzo de 1963.

79 Dicho suplicatorio fue denegado por oficio del presidente de las Cortes el 28 de junio de 1968. 
gánicas, si bien atribuyendo la facultad de autorizar los suplicatorios a la Cámara —en lugar de a su presidente- y el trámite a una Comisión Especial de Suplicatorios - en lugar de a la Comisión Permanente ${ }^{80}$.

Posteriormente fue promulgada la Constitución que consagró la inmunidad con la siguiente fórmula: «Durante el período de su mandato los diputados y senadores gozarán asimismo de inmunidad y sólo podrán ser detenidos en caso de flagrante delito. No podrán ser inculpados ni procesados sin la previa autorización de la Cámara respectiva» ${ }^{81}$. Este precepto es de hechura clásica; es, por tanto, confirmatorio de una larga tradición, como lo acredita la circunstancia de que fuese aprobado por ambas Cámaras sin enmiendas, apenas discusión y ningún voto en contra 82 .

Poco tiempo ha transcurrido en esta nueva etapa de la inmunidad, pero no deja de ser significativo que durante unos tres años y medio de vida en el Congreso de los Diputados sólo se hayan presentado tres suplicatorios por apología al terrorismo y resistencia grave a los agentes de la autoridad, habiéndose denegado uno y concedido dos ${ }^{83}$.

Si esta línea de conducta se confirma, cabe pensar que la inmunidad está entrando en vía de desuso, lo cual sería la mejor forma de consolidar su extinción ${ }^{84}$.

80 El art. 19 del Reglamento provisional del Congreso de 17 de octubre de 1977, está montado sobre el art. 9 del Reglamento de 15 de noviembre de 1971 y el art. 44 del Reglamento de 29 de noviembre de 1934. Prácticamente es idéntico el art. 36 del Reglamento provisional del Senado de 18 de octubre de 1977.

${ }^{81}$ Artículo 71.2 de la Constitución de 27 de diciembre de 1978.

$\approx \mathrm{La}$ inmunidad fue recogida en el Proyecto de Constitución (art. 63.2 en el Boletín Oficial de las Cortes, núm. 44, de 5 de enero de 1978). No se presentaron enmiendas a su texto en el Congreso, y en la Comisión de Asuntos Constitucionales y Libertades públicas es aprobado el texto por unanimidad (Diario de Sesiones de dicha Comisión del día 2 de junio de 1978, núm. 80, pág. 290), y así se publica en el Boletín Oficial de las Cortes, número 121 , de 1 de julio de 1978, si bien por haber habido corrimiento en la numeración de artículos le corresponde el núm. 66-2. En el Pleno del Congreso es votado este artículo 66-2 sin debate y aprobado por 278 votos a favor, ninguno en contra y ninguna abstención (Diario de Sesiones del Congreso del día 12 de julio de 1978, núm. 108), publicándose el Proyecto de Constitución aprobado por el Congreso de los Diputados en el Boletín Oficial de las Cortes, núm. 135, de 24 de julio de 1978. En la tramitación en la Cámara Alta, tampoco se presentaron enmiendas al texto regulador de la inmunidad, y en la Comisión es aprobado sin debate (Diario de Sesiones del Senado de 31 de agosto de 1978, número 47, pág. 2185). El Boletín Oficial de las Cortes, núm. 157, de 6 de octubre de 1978, publica el aludido precepto con el número $70-2$ por haber habido un nuevo corrimiento de artículos. Tramitado el texto en el Pleno del Senado, también es aprobado sin debate y por unanimidad de los ciento setenta y seis senadores presentes (Diario de Sesiones de 29 de septiembre de 1978, núm. 62, pág. 3131). Y sin ninguna rectificación es publicado el art. 70-2 en el Boletín Oficial de las Cortes, núm. 161, de 13 de octubre de 1978, que tras la reunión de la Comisión Mixta pasó a ser definitivamente el art. 71-2 (Boletin Oficial de las Cortes, núm. 170, de 28 de octubre de 1978), y como tal, fue sometido a referéndum popular, sancionado por el Rey en solemne Sesión conjunta del Congreso y del Senado, celebrada en el Palacio de las Cortes el 27 de noviembre de 1978, y publicada en el Boletín Oficial del Estado de 29 de noviembre de 1978.

${ }_{83}$ Diario de Sesiones de 1979, núm. 35 (pág. 2119) y núm. 47 (pág. 2949).

${ }^{84} \mathrm{El}$ nuevo texto de Reglamento del Congreso, en trámite de elaboración, regula la inmunidad en forma tradicional, aunque con alguna mayor precisión en sus artículos 11 a 14 (Boletín Oficial de las Cortes, de 11 de julio de 1980). 


\section{SISTEMAS COMPARADOS}

Hasta cuatro sistemas tipo de inmunidad cabe configurar en el Derecho comparado. Son el inglés, el francés, el soviético y el de los nuevos Parlamentos.

En Inglaterra, la inmunidad constituye una tradición secular consolidada que ha desembocado en desuso. En efecto, a la vieja democracia inglesa no le hace falta ser defendida por ortopedias privilegiadas de ningún género. Por una parte, en las causas civiles la inmunidad dejó de tener vigencia a partir de 1838 , en que se abolió la prisión por deudas ${ }^{85}$. Por otra parte, en las causas criminales la inmunidad nunca favoreció a los parlamentarios en los supuestos clásicos de treason, felony, and breach of peace ${ }^{86}$, y la práctica fue ampliando estos difusos conceptos penales hasta que quedó excluida la inmunidad en todas las causas penales, según declaración que en 1641 hicieron los Lores conjuntamente con los Comunes, en la que se precisaba que «el privilegio parlamentario es concedido para el servicio del común, y no para ser usado en peligro del común» ${ }^{87}$. Posteriormente aún hubo mayores precisiones para supuestos de imprenta, tan dispuestos a ser declarados inmunes en países latinos ${ }^{88}$. En conclusión, el Parlamento británico disfruta de una inmunidad nominal que se reduce a que las Cámaras deben ser informadas de las causas y sentencias que impliquen a los parlamentarios. Esta misma tónica sigue los Estados Unidos, cuya Constitución alude expresa y textualmente a que la inmunidad no ampara los casos de treason, felony, and breach of peace ${ }^{89}$, y Constituciones de algún Estado federado - como las de Vermont, Nueva York, Virginia y Carolina del Norte- ni siquiera aluden al privilegio, que es inexistente ${ }^{90}$. Otros países que siguen esta misma línea son las democracias bien asentadas de Australia, Canadá y Holanda ${ }^{91}$.

El sistema soviético reconoce formalmente la inmunidad ${ }^{92}$. Son pocos los datos que se disponen de su vigencia en la realidad política de la URSS ${ }^{93}$,

${ }^{85}$ May afirma que «freedom from arrest has lost almost all its value since as a result of the Judgments Act, 1838, s. I, and subsequent legislation, imprisonment in civil process has been practically abolished» (ob. cit., pág. 93).

${ }^{86}$ Larke's case, 1429 , citado por E. May.

5 E. May, ob. cit., pág. 103.

${ }_{83} \mathrm{E}$. May cita el caso Creasury (referido en otra parte de este trabajo, así como el caso de John Wilke, de 1793, en que ambas Cámaras resolvieron «que el privilegio parlamentario no ampara el caso de escribir y publicar libelos sediciosos» (ob. cit., pág. 104).

${ }^{9}$ E1 artículo 1 , secc. 6.", núm. 1 de la Constitución, se transcribe en la nota 5 de este trabajo.

${ }_{90}$ En este sentido, véase el clásico libro de H. S. Cushing, Elements of the Law and Practice of Legislative Assemblies in the United States of America, 9.' ed., Boston, 1874, páginas 226 y 227 , en el que terminantemente se afirma que la norma general es que no existe privilegio parlamentario para cualquier causa o procedimiento criminal (pág. 228).

${ }^{91}$ La Asociación de Secretarías Generales de los Parlamentos ha publicado un folleto sobre «Privileges and Immunities of Parliament and Members of Parliament», Ginebra, 1977, 3..$^{2}$ serie, núm. 110, sobre la base de un cuestionario distribuido entre cincuenta Parlamentos de todo el mundo, y que ofrecen datos actuales de sumo interés para encajar a cada país dentro de los sistemas a que se refiere este trabajo.

${ }_{92}$ Véase art. 107 de la Constitución de la URSS, de 1977, que se transcribe en la nota 6 de este trabajo.

${ }_{93}$ El folleto a que se ha hecho antes referencia, y que ha sido publicado por la Asso- 
pero todo hace' suponer que, por razones bien distintas a las del mundo occidental, la inmunidad se halla confinada en un reducto estrictamente formal. En efecto, existen diversas circunstancias que favorecen este aserto. Primeto es la inexistencia de libertades, que da pocas posibilidades al sistema de publicidad, deliberación y discusión que exige todo Parlamento. En segundo lugar, el dominio del partido único hace imposible los enfrentamientos políticos y nada tienen que temer los parlamentarios de acciones maliciosas y tendenciosas que les impidan ejercitar su función dentro de otra alternativa que no sea la disciplina del partido. Finalmente, está probado que en los sistemas totalitarios las infracciones penales se reducen muy considerablemente, siendo difícilmente concebibles delitos de prensa, de injurias, de subversión, etc., y si los cometiera un parlamentario, de poco le serviría la inmunidad declarada en la Constitución. Por todo ello, en la URSS y países satélites apenas tiene fundamento pensar en el privilegio o prerrogativa de la inmunidad parlamentaria.

Un tercer sistema podría agrupar a cuantos países nuevos emergen a la democracia y. desean hacerlo dentro del modelo clásico. La mayor parte de los países en el mundo surgen a la independencia después de la segunda mitad del siglo $\mathrm{xx}, \mathrm{y}$ cualesquiera que sean sus Constituciones formales, la realidad es que les falta tradición, asentamiento y hábito político para encasillarlos en ninguno de los sistemas anteriores. En verdad que países como Zaire y Tanzania, que contestaron recientemente al cuestionario que sobre privilegios parlamentarios les fue remitido desde Ginebra por la Asociación de Secretarías. Generales de Parlamentos, no pueden por el momento ser incluidos en otro grupo más que en éste de indeterminados.

Dejamos para el final el modelo francés, que se ha extendido al mundo latino. Este sistema es muy similar al español y ampara a los parlamentarios de detenciones y procesos criminales siempre que no medie previa autorización del Parlamento. No ampara los casos civiles ni los correccionales o de meras faltas. Tampoco queda protegido el diputado en caso de flagrante delito, por la circunstancia de que en estos supuestos la sospecha de pasión política desaparece. La inmunidad sólo juega durante el período de sesiones, y no en vacaciones o suspensiones, en que no hay ninguna función parlamentaria que proteger. La práctica parlamentaria ha ido encajando la inmunidad en cauces cada vez más reglados y estrechos, puesto que a veces ha jugado en contra de los propios parlamentarios ${ }^{94}$. En otras ocasiones se ha abusado del privilegio, como en los delitos de prensa, en los que tradicionalmente se ha venido denegando la autorización para procesar, y que ha sido aprovechado

ciation of Secretaries General of Parliaments, afirma que «el modelo en los países socialistas no ha sido examinado adecuadamente por no haber sido contestado el cuestionario por la mayor parte de Parlamentos que representan este sistema» (pág. 119).

${ }_{94}$ Barthélemy afirma que «la persona que quiere difamar sobre seguro y barato a un parlamentario tiene este medio muy cómodo: "dirige al presidente de la Asamblea una petición de autorización para proceder, en la que expone todos sus agravios. La petición se imprime a cuenta de la Asamblea, se distribuye a todos los colegas del diputado perseguido, se comunica a la prensa, y queda para la historia, en los archivos del Parlamento'. El particular tiene su venganza» (Précis de Droit Constitutionnel, París, 1936, pág. 300). 
por sectores extremistas para nombrar director de periódico a un parlamentario, que de esta forma cubría con su irresponsabilidad al periódico ${ }^{95}$.

Este último sistema ha sido el modelo más seguido. Lo han adoptado Bélgica, Italia, Alemania, Japón, Finlandia, Dinamarca, Egipto, Israel, etc. La práctica varía mucho según los países, si bien la tónica general es que la inmunidad está tanto más devaluada cuanto más arraigada se halla la democracia.

En conclusión, la inmunidad es una prerrogativa que tiende a caer en desuso y que, frente a la opinión pública, juega como una desigualdad difícilmente justificable dentro de la democracia.

\section{INMUNIDAD Y FUTURO}

No es razonable vaticinar la pronta desaparición de la inmunidad. Mucho menos es presumible tal resultado dentro del Derecho parlamentario español, habida cuenta de la consagración constitucional de la idea; pero resulta esperanzador el declive que en estos últimos años se viene observando en cuanto a su uso, y que confirma la aspiración manifestada por Silvela hace ya más de medio siglo $\%$.

Realmente, más que una abolición del privilegio, sería más eficaz que cayera en desuso, y mientras no se produzca este deseable efecto resultaría muy constructivo que la inmunidad en el futuro se atuviera a los siguientes principios o requisitos.

1. Que la inmunidad juegue solamente cuando las Cámaras están reunidas, pues en períodos de vacaciones o de suspensión no existe función parlamentaria que deba ser protegida.

2. Que, no existiendo la especie de delito político en las democracias, resulta poco justificada la específica protección que se da a los parlamentarios ante acciones judiciales sin intencionalidad política, y desde luego resulta inicua la protección frente a delitos comunes como puedan ser el homicidio, el robo o la malversación.

3. Podrían ser objeto de consideración transitoria especial los delitos de palabra y prensa, tales como las posibles injurias que contengan los discursos en reuniones políticas o los artículos de prensa, habida cuenta de la especial susceptibilidad ante juicios de intenciones. Pero todo ello sin olvidar que la democracia, y los parlamentarios deben ser ejemplo de responsabilidad en el decir y en el hacer.

4. ${ }^{\circ}$ La inmunidad concedida debe interrumpir el plazo de prescripción del delito imputado, de manera que una vez cesada la función parlamentaria no quede consagrada la impunidad.

5. Se debe mantener informado al Parlamento de cuantas incidencias

95 Según Barthélemy, ha sido ésta una práctica comunista que ha provocado la proposición Alcide Delmont, el 29 de junio de 1927, tratando de cortar este abuso (op. cit., página 300).

\$6 Silvela, ob. cit., pág. 33. 
puedan adoptarse contra la libertad personal del parlamentario, ya sea detenciones, procesamientos o sentencias condenatorias.

6..$^{\circ}$ Excepcionalmente, el Parlamento debería poder no exculpar el hecho o la condena, pero sí solicitar la presencia del diputado detenido o preso para que pueda ejercitar su función parlamentaria dentro de la Cámara.

7. Los suplicatorios deberían presumirse otorgados transcurrido un breve plazo de silencio de la Cámara.

8..$^{\circ}$ Frente a la restricción de la inmunidad, podría en cambio ampliarse la prerrogativa a ciertas molestias, que podían ser ahorradas al diputado, como es la comparecencia como testigo en juicio, problemas de servicio militar, facilidades administrativas para su gestión como parlamentario, etc.

La conclusión es que si se cumplieran todos estos principios, la inmunidad ganaría prestigio, a la vez que se iría difuminando en el futuro. 